\title{
RESPONSABILIDAD RESTRINGIDA POR LA EDAD EN LA COMISIÓN DE DELITOS GRAVES Y LA JURISPRUDENCIA DE LAS SALAS DE LA CORTE SUPREMA
}

\section{RESPONSIBILITY RESTRICTED BY AGE IN THE COMMISSIONON SERIOUS CRIMES AND THE JURISPRUDENCE OF THE HALLS OF THE SUPREME COURT}

\author{
Jeannette Oyarce Delgado \\ Docente \\ Universidad de San Martín de Porres \\ jane1005@hotmail.com \\ Perú, Lima
}

\section{SUMARIO}

- Introducción

- Igualdad

- Ciencias penales

- Culpabilidad

- Responsabilidad restringida por la edad

- La pena

- Acuerdo Plenario N 4-2016/CIJ-116

- Jurisprudencia de la Sala Constitucional y Social de la Corte Suprema

- Conclusiones

\section{RESUMEN}

La Corte Suprema de Justicia, emite ejecutorias y acuerdos plenarios con efectos vinculantes, respecto a la interpretación y aplicación de las normas que conforman nuestro ordenamiento legal, con la finalidad de consolidar y uniformizar los criterios asumidos y de esta manera coadyuvar a la predictibilidad y seguridad del sistema de justicia de nuestro país.

Cuando las Salas Penales y Constitucionales de la Corte Suprema, emiten pronunciamientos disímiles frente a un mismo dispositivo legal, surge duda e incertidumbre respecto a cómo interpretar y aplicar dicha norma; es el caso, del artículo $22^{\circ}$ del Código Penal, el mismo que prevé la disminución de la pena cuando el sujeto activo del delito cuenta entre 18 y 21 años o es mayor de 65 años de edad. Por un lado las Salas Penales de la Corte Suprema, en reiterada jurisprudencia y acuerdos plenarios, señalan que las restricciones por delitos graves, vulneran el principio de igualdad y son discriminatorias; por otro lado, las Salas Constitucionales de la Corte Suprema, mayoritariamente han venido desaprobando las consultas efectuadas respecto a la inaplicabilidad de esa limitación para la disminución de la pena, señalando que no son inconstitucionales ni afectan el principio de igualdad.

Nosotros consideramos que, si bien es cierto, las restricciones incorporadas por el legislador son incongruentes y constituyen una clara manifestación de una inadecuada política criminal que contraviene los estudios dogmáticos, también es cierto, que esta limitación no atenta contra el principioderecho de igualdad y menos aún, constituye una norma discriminatoria.

\begin{abstract}
The national court of justice, emits enforceable and plenary accords with binding effects respect to the interpretation and application of the substantive rules and procedures. Which forms our legal order with the finally purpose of consolidate and unify the assumed criteria, in this way help predictability and legal security the justice system of our country.
\end{abstract}


But when the criminal rooms and the constitutional branches of the Supreme Court, have dissimilar procedures in front of the same legal device, the doubt arises and uncertainty respect how to interpret and apply this rule, this is the case of the article 22 of the penal code, which provides the reduction penalty for agents called young, adult and older adults, this is when the active subject has the age between of 18 and 21 years or older to 65 years old. In one hand the Criminal Supreme Room, repeated jurisprudence and agreements plenary, designates that the restrictions by serious crimes violate the principle of equality and are discriminatory, in another way the brands constitutional, had been disapproving in the majority about consultations carried out in respect to the inapplicability of this limitation for the decrease in grief, pointing that are not unconstitutional don't affect a principle of equality.

We considerate that, if it's true the incorporate restrictions by the legislator are inconsistent and are clear manifestation inadequate criminal policy that are against dogmatic studies, also is true that this limitation doesn't affect against with the principle right of equality and less is a discriminatory rule.

\section{PALABRAS CLAVE}

Culpabilidad; discriminación; igualdad; imputabilidad disminuida; pena; responsabilidad restringida.

\section{KEYWORDS}

Guilty; discrimination; equality; disminished imputability; pain; restricted liability.

\section{INTRODUCCIÓN}

El artículo $22^{\circ}$ del Código Penal, prevé la disminución de la pena del agente que cuenta entre 18 y 21 años o es mayor de 65 años de edad, este dispositivo ha sido modificado a fin de restringirse dicha atenuación en razón a la comisión de algunos delitos que son considerados graves, así paulatinamente, se ha ido incrementando un listado de delitos cuyos autores o partícipes no serían acreedores a esta atenuación de la pena. Esta norma ha sido objeto de reiterados pronunciamientos por parte de los magistrados de los Juzgados y Salas Penales, las mismas que efectuando un control difuso inaplican dicha restricción, considerando que es inconstitucional, por afectar el principio de igualdad y por ser discriminatoria.

Conforme lo dispone el artículo 14 de la Ley Orgánica del Poder Judicial, las sentencias que aplican el control difuso deben ser elevadas en consulta a la Sala Constitucional y Social de la Corte Suprema, la misma que en la mayoría de los casos, las ha desaprobado; asimismo, en la Consulta del EXP. $\mathrm{N}^{\circ} 1618-2016$, de fecha 16 de agosto de 2016, publicada el 7 de diciembre de 2017, ha establecido que lo expuesto en el segundo fundamento constituye "doctrina jurisprudencial vinculante".

Por su parte los Vocales de las Salas Penales de la Corte Suprema, a fin de concordar y definir acuerdos jurisprudenciales, realizaron el X Pleno Jurisdiccional emitiendo el Acuerdo Plenario $\mathrm{N}^{\mathrm{o}}$ 004-2016/CJ-116, de fecha 12 de junio de dos mil diecisiete, publicado el 17 de octubre del citado año, en el cual concluyeron que las exclusiones resultan inconstitucionales y los jueces penales ordinarios no deben aplicarlas.

Por consiguiente, se advierte que la Jurisprudencia de Sala de Derecho Constitucional y Social Permanente Corte Suprema de Justicia, y el citado Acuerdo Plenario, emiten pronunciamientos disimiles, sin embargo, ambos precisan que sus fundamentos constituyen doctrina jurisprudencial vinculante para todos los jueces del Poder Judicial, conforme es de verse del primer punto de la decisión de la Ejecutoria Suprema y los puntos $25^{\circ}$ al $27^{\circ}$ del Acuerdo Plenario.

Consideramos que es de suma importancia, analizar las citadas restricciones a fin de coadyuvar al análisis y debate sobre la citada disposición, para verificar si nos encontramos ante una norma que vulnera el principioderecho de igualdad, el mismo que constituye uno de los pilares de todo ordenamiento jurídico en un Estado Democrático de Derecho o si nos encontramos frente a un trato diferenciado frente a situaciones de hecho distintas y ante una inadecuada política criminal por parte del Estado.

Para estos efectos, resulta pertinente efectuar reflexiones sobre la igualdad, trato diferenciado, discriminación, culpabilidad, la pena y la determinación judicial de la pena. 
de delitos graves y la jurisprudencia de las salas de la Corte Suprema

Responsibility restricted by age in the commissionon

serious crimes and the jurisprudence of the halls of the Supreme Court

\section{- Igualdad}

Constituye un principio y derecho de nuestro ordenamiento legal, propio de un Estado Constitucional y democrático de derecho en el cual todos los ciudadanos gozamos de los mismos derechos y obligaciones, por consiguiente, debemos ser tratado del mismo modo en la ley y ante la ley.

Conforme ha precisado el Tribunal Constitucional, el principio de igualdad:

Constituye parte del núcleo del sistema constitucional de fundamento democrático. Como derecho fundamental comporta el reconocimiento de la existencia de una facultad o atribución conformante del patrimonio jurídico de la persona, derivada de su naturaleza, que consiste en ser tratada igual que los demás en hechos, situaciones $\mathrm{o}$ acontecimientos coincidentes, por ende deviene en el derecho subjetivo de obtener un trato igual y evitar privilegios y desigualdades arbitrarias. (STC 0004-2006-PI, fundamento 116)

\section{Al respecto, Gutiérrez (2010), precisa:}

Que el derecho de igualdad a su vez, tiene dos dimensiones: formal y material. En su dimensión formal, impone una exigencia al legislador para que éste no realice diferencias injustificadas; pero también a la administración pública y a los órganos de la jurisdicción, en el sentido de que la ley no puede aplicarse en forma desigual frente a supuestos semejantes. Y en su dimensión material, el derecho de igualdad supone una exigencia positiva por parte del Estado, que se inicia con el reconocimiento de la insuficiencia de los mandatos prohibitivos de discriminación y la necesidad de equiparar situaciones, per se, desiguales. (Pág. 85)

La importancia de la observancia del principio de igualdad en el derecho penal es resaltada por Meini (2014):

La prohibición de comportamientos socialmente disfuncionales y la imposición de penas solo se legitima a partir del principio de igualdad: así como aceptamos la restricción de la libertad de actuación de terceros para proteger nuestra propia libertad y así como admitimos que se sancione a quien interfiere en el ejercicio de nuestra libertad, de igual manera habremos de acceder a que se restringa nuestra libertad de actuación para proteger a terceros y que se nos sancione si no lo hacemos. No hay libertad sin igualdad y todos somos iguales ante la ley penal. (Pág. 27)

\section{- Trato diferenciado}

En la sociedad existen diferencias económicas, sociales y culturales ello conlleva a que algunas personas encuentren limitaciones en la satisfacción de sus necesidades, así como en el desarrollo de su proyecto de vida, por ello, a fin de lograr una igualdad material, el Estado, dicta políticas a fin disminuir esta desigualdad y lograr cierta equiparidad.

\section{Lascurain (2011) señala:}

Lo que el principio de igualdad formal le impone al legislador es que sea razonable al hacer diferencias, en el sentido de que, como en principio está mal distinguir lo que parece objetivamente igual, pueda sustentar su estrategia en la consecución de una finalidad loable y cuya loabilidad supere el malestar que nos produce la distinción misma, acota que la igualdad formal es un derecho a que no se nos diferencie irrazonablemente en el tratamiento jurídico: a que no se establezca irrazonablemente que nuestra situación o nuestra conducta es distinta a la conducta aparentemente igual de otra persona que resulta mejor tratada. (Pág. 59)

Por consiguiente, el trato diferenciado vulnera el principio de igualdad, cuando éste se encuentra desprovisto de una justificación, además, cuando dicha medida no es razonable y proporcionada en atención a los fines que se busca alcanzar con dicho trato. En este sentido se ha pronunciado en reiterada Jurisprudencia el Tribunal Constitucional Exp.0606-2004AA/TC:

Tratar igual a los iguales y desigual a los desiguales, no se traduce en el derecho a ser objeto del mismo trato, con independencia del contexto o las circunstancias en las que un sujeto se encuentre, sino a que se realice un tratamiento diferenciado si es que dos sujetos no se encuentran en una situación igual. Por tanto, el problema es determinar qué tratos diferenciados son constitucionalmente admisibles, lo que deberá analizarse en cada caso concreto, conforme al test de razonabilidad y proporcionalidad. (Fundamento 11)

De lo que se colige que no todo tratamiento desigual constituye una vulneración al principio de igualdad, admitiéndose el tratamiento desigual, basado en razones objetivas, el mismo que debe ser proporcionado. 


\section{- Término de comparación}

Respecto al término de comparación, el Tribunal Constitucional al respecto ha señalado en el Exp. $\mathrm{N}^{\circ}$ 05157-2014-PA/TC:

b) La situación jurídica propuesta como término de comparación debe ostentar propiedades que, desde un punto de vista fáctico y jurídico, resulten sustancialmente análogas a las que ostenta la situación jurídica que se reputa discriminatoria. Desde luego, ello no implica exigir que se traten de situaciones idénticas, sino tan solo de casos entre los que quepa, una vez analizadas sus propiedades, entablar una relación analógica prima facie relevante. Contrario sensu, no resultará válido el término de comparación en el que $a b$ initio pueda apreciarse con claridad la ausencia (o presencia) de una propiedad jurídica de singular relevancia que posee (o no posee) la situación jurídica cuestionada. (Fundamento 54)

Consideramos que el X Pleno adolece de un término de comparación válido ya que la situación fáctica no es la misma, si bien nos encontramos ante conductas típicas, antijurídicas y culpables, los elementos objetivos de los tipos penales son distintos, el desvalor de la acción y del resultado difieren, no pueden ser consideradas situaciones de hecho análogas.

\section{- Discriminación}

La discriminación constituye un trato diferenciado basado en condiciones inherentes a la persona tales como género, raza, idioma, condición económica, filiación política, orientación sexual o circunstancias similares. Nuestro ordenamiento penal ha incorporado mediante la Ley 27270 , la figura delictiva de discriminación e incitación a la discriminación, prevista y sancionada en el artículo 323 del Código Penal, que reprime actos de distinción, exclusión, restricción o preferencia que anulan o menoscaban el reconocimiento, goce $\mathrm{o}$ ejercicio de cualquier derecho de una persona, basados en dichos o similares motivos.

Courtis Christian, citado por Oscar Parra Vera (2008) precisa:

\footnotetext{
La "discriminación", es una violación "agravada" del principio de igualdad, que no es "cualquier forma arbitraria de menoscabo de un derecho", sino que se basa en "la existencia de preconceptos o prejuicios contra un grupo social determinado, que tienen como efecto la exclusión de ese grupo del goce o ejercicio de
}

derechos, y el consiguiente agravamiento de su exclusión o marginación social”. (Pág. 135)

En este sentido, resulta pertinente precisar que no todo trato diferenciado arbitrario o injustificado es discriminatorio, puede afectar el principio-derecho de igualdad, pero no por ello debe ser considerado discriminatorio, en este sentido lo ha señalado por Cerdá (2005):

La prohibición de discriminación no debe ser confundida con el principio de prohibición de trato desigual, la primera es un instrumento que excluye la posibilidad que sean tomadas en cuenta como circunstancias relevantes la raza, el sexo, religión etc. Mientras que la segunda es la prohibición de efectuar distinciones o diferencias arbitrarias, sin justificación. Acota que existe una confusión de estos conceptos, que se utilizan en forma indistinta. (Pág. 196)

Por consiguiente, las restricciones efectuadas en el artículo $22^{\circ}$ del Código Penal no son discriminatorias, ya que no se basan o fundamenta en la diferenciación de un grupo de personas por sus características innatas, incorporadas o adoptadas, sino en los delitos que han efectuado.

\section{CIENCIAS PENALES}

\section{Política criminal}

Constituye función del Estado elaborar y promulgar normas jurídicas con la finalidad de coadyuvar a una convivencia pacífica en la cual se respete los derechos y libertades de los ciudadanos, por ello se incriminan determinadas acciones que vulneran bienes jurídicos, conminándolas con una determinada consecuencia jurídica.

La política criminal tiene una estructura interdisciplinaria, siendo una ciencia jurídica, política y sociológica, por ello, al fijar una pena a una determinada conducta, no se debe obviar tener presente los fines y fundamento de la pena, observando los principios limitadores del derecho penal, así como, los estudios dogmáticos sobre la teoría del delito. De igual forma, debe tener presente el conocimiento científico sobre el surgimiento de la criminalidad y la lucha contra ella, proporcionados por la criminología, lamentablemente ello no acontece en nuestro país, hace ya varias décadas, el Parlamento viene legislando para contentar los reclamos de la población, la misma que llevada por una 
de delitos graves y la jurisprudencia de las salas de la Corte Suprema

Responsibility restricted by age in the commissionon

serious crimes and the jurisprudence of the halls of the Supreme Court

sensación de inseguridad reclama sanciones "ejemplarizadoras", muestra de ello las encontramos en las últimas modificaciones efectuadas al Código Penal, 3 ejemplos:

a. Artículo 108 B: se ha incorporado como circunstancia agravante " 9 . Si el agente actúa en estado de ebriedad, con presencia de alcohol en la sangre en proporción mayor de 0.25 gramos-litro, o bajo efecto de drogas tóxicas, estupefacientes, sustancias psicotrópicas o sintéticas".

Por el contrario, los efectos del alcohol, drogas o sustancias estupefacientes, ya sean estimulantes, depresoras o alucinógenas actúan sobre el sistema nervioso central del cerebro, inhibiendo las vías reguladoras, responsable de la planificación de acciones, autocontrol e inhibición de impulsividad, por ello, esta circunstancia, en la mayoría de los casos es considerada para disminuir la punibilidad del agente, y si el agente dolosamente se coloca en esta situación, consumiendo alcohol o drogas para cometer el delito, sería acreedor a la disminución de la punibilidad por dicha ingesta, en atención al actio libera in causa.

Las circunstancias agravantes son accidentales al delito, inciden en el ilícito penal, modificando la responsabilidad del sujeto activo del delito, elevando la sanción a imponer, porque hay un mayor desvalor de la acción o del resultado. Siendo así, no existe sustento para considerar la ingesta de alcohol como una circunstancia agravante, lo que evidencia un desconocimiento de los estudios científicos y dogmático penales, demostrando una política criminal deficiente.

b. Artículo 173: "El que tiene acceso carnal por vía vaginal, anal o bucal o realiza cualquier otro acto análogo con la introducción de un objeto o parte del cuerpo por alguna de las dos primeras vías, con un menor de catorce años, será reprimido con pena de cadena perpetua"

Se legisla con la errónea idea que, incrementando las penas, la incidencia de la comisión de delitos disminuirá, cuando las estadísticas nos demuestran que ello no es cierto. Al imponer una pena tasada se impide que el Juzgador pueda individualizar adecuadamente la pena, teniendo en consideración las circunstancias que han rodeado el evento, así como las condiciones personales del agente. Pondré a consideración 2 supuestos: A) con 21 años de edad, mantiene una relación sentimental con su enamorada de 13 años $\mathrm{y}$ voluntariamente mantienen relaciones sexuales. B) con 21 años de edad intercepta a una menor de 9 años, con engaños la lleva a un lugar apartado y la violenta sexualmente.

Ambos casos se encuentran sancionados con cadena perpetua, a pesar que el desvalor de la acción y del resultado son muy distintos, el juzgador no podría individualizar la pena conforme corresponde, al respecto, es pertinente mencionar lo señalado por Zaffaroni, citado por Mendoza Ayma (2015):

Toda teoría del derecho penal, debe establecer la vinculación del delito con la pena, (...) es la base de la individualización de la pena. Este elemento vinculante es una necesidad y toma el nombre de conexión punitiva, es imprescindible, pues no es ético ni razonable pretender, que el contenido antijurídico de un injusto indique la cantidad de la pena exacta a imponerse, pues supondría asumir una sociedad robótica con seres ónticamente idénticos e inmutables. (Pág. 137)

Si bien es cierto, los delitos de feminicidio y violación de menores tienen una alta incidencia en nuestro país y requieren de acciones coordinadas por parte de las instituciones del Estado, resulta sumamente cuestionable que se pretenda "luchar" contra estas conductas delictivas, elevando indiscriminadamente las penas o introduciendo inexistentes circunstancias agravantes, ello es muestra de una inadecuada e inadmisible política criminal y del ejercicio de un derecho penal simbólico.

c. Restricciones al Artículo 22 del Código Penal.

El citado numeral faculta disminuir la pena a los jóvenes que se encuentran entre 18 y 21 años de edad y a los adultos que superan los 65 años, tiene su fundamento para los primeros, en su falta de experiencia de vida y en que serían más impulsivos, irreflexivos e influenciables y en el caso de los segundos porque sus facultades se encontrarían disminuidas por la senilidad. 
Si el legislador considera que existe un menor reproche o menor exigencia para estos agentes, por tener menor capacidad para adecuar su conducta conforme a derecho, entonces no debería efectuar ninguna restricción por la comisión de determinados delitos que revisten mayor gravedad, ya que un supuesto corresponde a la culpabilidad y el otro a la antijuricidad como elementos del delito. Por consiguiente, se advierte que en este caso se ha legislado contrariando los estudios dogmáticos de la teoría del delito, puesto que no debería efectuarse esta restricción teniendo en consideración la gravedad de los delitos. La mayoría de la legislación comparada no prevé esta disminución, si el legislador peruano ha considerado incorporarla, no debería efectuar restricción por razón del delito.

Resulta necesario que el Estado desarrolle una política criminal teniendo en consideración estudios de nuestra realidad social, del origen e incidencia de las actividades delictivas, contando con datos estadísticos a fin de poder llevar a cabo estrategias a mediano y largo plazo, con el concurso de instituciones como los ministerios de Salud, de Educación, de la Mujer y Poblaciones Vulnerables, etc., estructurando una política criminal que nuestro país necesita.

\section{Dogmática penal}

Villavicencio (2012) "Es la disciplina que se ocupa del estudio general, abstracto, sistemático, crítico y axiológico de las normas del Derecho Penal Positivo. Sirve de garantía para la aplicación racional, segura y uniforme del Derecho Penal como límite a la arbitrariedad" (Pág. 25).

Sirve para un adecuado conocimiento de las normas del Derecho Penal, las mismas que deben ser interpretadas bajo los lineamientos de nuestra Constitución Política del Estado, los Principios del Derecho Penal y las teorías elaboradas sobre la materia, de esta manera coadyuvar la labor del sistema de justicia penal.

Lamentablemente, la determinación judicial de la pena, las circunstancias atenuantes, agravantes o las causales de disminución de la punibilidad, no han sido objeto de un profundo estudio; asimismo, la judicatura hasta hace unas décadas no sustentaba o justificaba la individualización de la pena, por ello se mencionaba que al fijar la sanción penal, no hacía uso de discrecionalidad sino de arbitrariedad, felizmente esa situación ha variado paulatinamente, puesto que, en los dos últimos decenios se han efectuado Plenos Jurisdiccionales con tal finalidad y se vienen realizando estudios pero aún no existe consenso sobre los conceptos que se utilizan al individualizar la pena.

\section{CULPABILIDAD}

También denominada imputación personal. (Maurach, 1994), precisa:

Mediante el juicio de desvalor de la culpabilidad se reprocha al autor el no haberse comportado conforme a derecho, el haberse decidido por el ilícito, no obstante haber podido actuar conforme a derecho, por consiguiente, es culpable quien infringe las normas de deber, al no hacer un uso adecuado de su poder, encontrándose en la capacidad de controlar sus impulsos condicionados ya sea por el medio o por una determinada predisposición. (Pág. 515)

De este modo, para que una persona pueda ser considerada culpable o pueda efectuarse un juicio personalizado de reproche personal por una conducta típica y antijurídica, es necesario, que se encuentren presentes las condiciones necesarias para ello, esto es, que sea imputable, que conozca la antijuricidad de la conducta y pueda exigírsele actuar de otro modo. Así la culpabilidad concebida normativamente es graduable y su cuantificación permite la determinación de la pena a imponer al agente.

\section{La imputabilidad}

La imputabilidad es esa capacidad de culpabilidad, la posibilidad de poder ser objeto de reproche penal, de poder exigirle haber actuado en forma distinta a la realizada, para tal efecto el sujeto activo debe tener la posibilidad de ser motivado por la norma, de ser consciente de su accionar, de las obligaciones que su entorno o la sociedad le imponen para posibilitar una convivencia pacífica. Hurtado (2011) precisa que "Una persona es imputable cuando posee la facultad de apreciar el carácter delictuoso de su acto y la facultad de determinarse conforme a esta apreciación" (Pág. 596). 
de delitos graves y la jurisprudencia de las salas de la Corte Suprema

Responsibility restricted by age in the commissionon

serious crimes and the jurisprudence of the halls of the Supreme Court

En sentido coincidente se pronuncia Villavicencio (2012) "La imputabilidad requiere de dos elementos: a) la capacidad de comprender la desaprobación jurídico penal y b) la capacidad de dirigir el comportamiento de acuerdo con esa comprensión” (Pág. 595). No es preciso que conozca los preceptos legales, sino únicamente de saber que su acción u omisión son contrarias al orden de la comunidad.

Para que la imputabilidad se halle ausente, se exige que el sujeto que ha realizado un comportamiento humano típico y antijurídico, sea incapaz de comprender el significado del mismo o de dirigir su actuación conforme a dicha comprensión. Se dará el primer presupuesto, cuando el agente se encuentra en una situación mental que le impide percatarse que su accionar está prohibido por el Derecho y el segundo presupuesto cuando el sujeto es incapaz de auto determinarse, de auto controlarse, de acuerdo a la comprensión del carácter ilícito del hecho.

Las personas mayores de 18 años de edad, son ciudadanos que poseen la capacidad de ser motivados por la norma y comprender la ilicitud de su accionar, mientras que los menores de edad, considerados inimputables, son sometidos al derecho tutelar al incurrir en una infracción a la ley penal ${ }^{1}$.

En algunos países la imputabilidad es desde los 16 años, como en Chile en el que debe establecerse el "discernimiento", es decir el estado mental del menor, de este modo el Juzgador debe verificar si efectivamente se encuentra en condiciones de comprender la ilicitud de sus actos.

\section{Responsabilidad}

El término responsabilidad es utilizado en nuestro código penal de 1991 como sinónimo de culpabilidad, pero doctrinariamente se formulan diferencias, al respecto (Roxin 2008) señala:

La noción de responsabilidad es de índole normativa, constituye una valoración del hecho

\footnotetext{
1 En algunos países la imputabilidad es desde los 16 años, como en Chile en el que debe establecerse el "discernimiento", esto es, el estado psicológico real del autor en el momento de ejecutar el hecho, lo que es propio de la fórmula mixta (la norma describe los estados que dan origen a la inimputabilidad, pero exige del juez una investigación ulterior sobre la existencia efectiva de la incapacidad para comprender y autodeterminarse.
}

típico y antijurídico, que permite determinar si se debe penar al autor culpable en la perspectiva de los fines de prevención del derecho penal, esta concepción permite reforzar la protección de las personas frente a la intervención punitiva del Estado: por un lado la culpabilidad sigue siendo el fundamento y límite de la pena: y por el otro, ésta no puede ser agravada por simples razones de prevención general o especial. (Pág. 31)

En similar sentido, (Rodríguez 2011) señala:

La responsabilidad penal ha de ser concebida como la consecuencia jurídica de la comisión de un delito, que se traduce en el estado de sometimiento al que queda sujeto un individuo frente a la potestad sancionadora estatal y que se materializa en la imposición de una pena. (Pág. 405)

\section{RESPONSABILIDAD RESTRINGIDA POR LA EDAD}

Se considera que la responsabilidad está atenuada cuando el agente se encuentra dentro del rango etario entre 18 y 21 años y más de 65 años de edad, el reproche o exigencia es menor, es un criterio objetivo para la determinación de la pena, una causal de disminución de la punibilidad.

Respecto a la imputabilidad disminuida, conforme se señalará en la investigación "Determinación de la pena y responsabilidad atenuada por la edad"

(...) etimológicamente el término capacidad es la cualidad del capaz en latín capax, que se deriva del verbo capere, es quien puede recoger o asumir tareas o funciones, consideramos que esta cualidad se posee o no, por lo que compartimos la postura de Ernest Von Beling, entre otros, quienes señalan que no es correcto el término imputabilidad disminuida, ya que no existen grados de imputabilidad. (Oyarce, 2016, Pág. 40)

Lo que concuerda con lo expresado por Cury (2005) cuando señala:

En el supuesto que el desarrollo de la personalidad aún no se ha completado o la salud mental se encuentra alterada, pero sin que ni lo uno ni lo otro excluyan completamente la capacidad de autodeterminación conforme a derecho, estos en rigor, no son problemas propios de la imputabilidad, pues ésta, como se desprende de su concepto, existe o no y, consiguientemente, no admite gradaciones. (Pág. 408) 
En el mismo sentido (Roxin 2008 pág. 849) precisa:

Los jóvenes, es decir, las personas que en el momento del hecho tienen dieciocho, pero aún no veintiún años, están equiparados a los adultos en cuanto a su imputabilidad. Las regulaciones especiales que la JGG [Ley de los Tribunales Juveniles de Alemania - Jugendgerichtsgesetz] prevé para ellos se refieren sólo a las consecuencias jurídicas.

De igual modo, Jescheck (1981) precisa:

La capacidad de culpabilidad disminuida no es una oscura categoría intermedia de semiimputabilidad, por el contrario, es una clase de capacidad de culpabilidad y se presenta por ello únicamente como una causa de atenuación facultativa de la pena por disminución de culpabilidad. (Pág. 608)

Por consiguiente, consideramos que los jóvenes adultos y adultos mayores no son imputables disminuidos o semi imputables, son personas que poseen capacidad de culpabilidad plena; su situación especial, debe ser analizada al individualizar la pena, etapa en la cual el juzgador deberá merituar el grado de culpabilidad del agente compulsando las circunstancias que han rodeado el evento delictivo y sus condiciones personales, verificando si concurren los fundamentos que justifiquen dicha atenuación, por consiguiente, no bastará con afirmar una culpabilidad disminuida, sino deberá analizarse si la impulsividad del agente, su falta de experiencia de vida o su personalidad manipulable o sugestionable condicionaron la comisión del evento delictivo materia de juzgamiento, por ello en el artículo $22^{\circ}$ el legislador consideró que dicha disminución es facultativa, teniendo en consideración cada caso en particular, en el mismo sentido lo dispone el artículo 46 1.h) que prevé como circunstancias atenuante: "La edad del imputado en tanto que ella hubiere influido en la conducta punible".

\section{LA PENA}

Es la consecuencia jurídica ante la comisión de una conducta delictiva, de este modo el autor va a ser privado de ciertos derechos o bienes jurídicos por haber vulnerado la norma tutelada por nuestro ordenamiento legal.
La pena es la limitación de los derechos del sujeto como consecuencia de la violación de un deber, que es conminada para impedir tal violación y tiene carácter heterogéneo respecto al contenido del mismo deber, son los instrumentos con los que el Derecho Penal persigue la prevención de los hechos ilícitos. Instrumentos no únicos ni siempre los más eficaces, sin embargo, son necesarios e irrenunciables para controlar, por parte de cada sociedad organizada, el crimen. (Pág. 547)

En efecto, la pena es un mal necesario al que debe recurrir el sistema de justicia penal, y de las concepciones que se han formulado sobre su finalidad, han predominado el preventivo general, preventivo especial así la teoría de la unión o teoría mixta, sin dejar de considerar la culpabilidad del agente. Nuestro Tribunal Constitucional también ha emitido pronunciamiento sobre esta:

Este Colegiado ya ha descartado que se conciba a la retribución absoluta como el fin de la pena. Ello, desde luego, no significa que se desconozca que toda sanción punitiva lleva consigo un elemento retributivo. (....) Las teorías preventivas, tanto la especial como la general, gozan de protección constitucional directa, en tanto y en cuanto, según se verá, sus objetivos resultan acordes con el principio-derecho de dignidad, y con la doble dimensión de los derechos fundamentales (STC. 0019-2005-PI, fundamento 37-38)

\section{Determinación judicial de la pena}

La individualización de la pena es una labor que el juzgador debe verificar teniendo en consideración la función preventiva general y especial de la pena, así como la culpabilidad del agente, para estos efectos se debe tener en consideración las circunstancias personales del agente, así como las circunstancias que han rodeado la comisión del evento delictivo.

Jescheck (1981) precisa: La determinación de las consecuencias jurídicas del hecho punible llevada a cabo por el juez conforme a su naturaleza, gravedad y forma de ejecución del delito, que elige una de las diversas posibilidades previstas legalmente, es una decisión que debe basarse en criterios valorativos objetivos, con una discrecionalidad jurídicamente vinculada. (Pág. 1189)

Su importancia también se considera política (Caro 2013 pág.3) señala:

Mantovani (2015) precisa: 
de delitos graves y la jurisprudencia de las salas de la Corte Suprema

Responsibility restricted by age in the commissionon

serious crimes and the jurisprudence of the halls of the Supreme Court

Se constata hasta qué punto los postulados del Estado democrático de Derecho concurren en la búsqueda de la "pena justa" que se transforma en el objetivo prioritario del sistema penal, entendiéndose la justa determinación del castigo como un acto del Estado contra un ciudadano, en el que deben concurrir simultáneamente los intereses y derechos de ambas partes.

En el sistema de determinación de la pena, los factores intervinientes en la cuantificación de la culpabilidad, se encuentran precisados en las disposiciones legales, lo que no acontecía hace algunos años; de igual forma, el aporte de la doctrina, y jurisprudencia en la individualización de la pena, se ha iniciado recién en las últimas décadas a diferencia de lo acontecido respecto a la teoría del delito, que ha sido abordada extensamente por la doctrina penal.

\section{Circunstancias atenuantes privilegiadas o causales de disminución de la punibilidad}

Como hemos señalado, la determinación judicial de la pena no ha sido objeto de estudios exhaustivos y recién hace unas décadas se han efectuado trabajos en la doctrina $y$ jurisprudencia sobre la misma, asimismo, no existe consenso sobre los conceptos que se deben tener en consideración para determinar judicialmente la pena, tal es el caso de la naturaleza de las previsiones contenidas en los artículos 13,14, 15, 16, 21, 22, 25 del CP, es decir, la disminución de la pena prevista por el legislador, en delitos de comisión por omisión, error de prohibición, error de comprensión culturalmente condicionado, tentativa, eximentes imperfectas, responsabilidad restringida por la edad y complicidad secundaria, esto es, si los mismos son causales de disminución de la punibilidad o son circunstancias atenuantes privilegiadas.

(Prado 2015 pág. 59) variando su posición inicial, precisa:

Que dichos presupuestos no constituyen circunstancias, ya que las circunstancias son externas al delito y estos son intrínsecas a él, acotando, que esos supuestos son causales de disminución de punibilidad, variando su posición inicial, puesto que, antes consideraba que constituían circunstancias atenuantes privilegiadas. Señala que son incorrectas las referencias a una eficacia atenuante para los citados casos, y que es dogmáticamente errada la referencia que realiza el Código Procesal Penal al referirse a estos supuestos.
Al respecto (Mirg Puig 2014) señala:

Las circunstancias modificativas son elementos accidentales del delito, en el sentido de que de ellos no depende el ser del delito, sino sólo su gravedad o cantidad. Aunque las eximentes incompletas afectan al injusto o su imputación personal, sólo determinan una disminución del quantum de gravedad de estos elementos, sin dar lugar a un cambio de delito. (Pág. 614)

Siendo así, la disminución de la punibilidad por razón del rango etario, constituye una circunstancia de atenuación, conforme se ha citado precedentemente

En el mismo sentido se pronuncia (Borja 2015 pág.15): "Que las circunstancias modificativas sean concebidas como elementos accidentales del delito, no significa que no puedan afectar a alguno de los componentes esenciales del mismo, especialmente las denominadas eximentes incompletas".

\section{Penas tasadas y desproporcionadas}

Lamentablemente como se ha referido en el punto III, en nuestro país el legislador ha venido incrementando las penas indiscriminadamente, son varios los delitos con circunstancias agravantes que se encuentran sancionados con cadena perpetua, sanción que es una expresión de la función especial negativa de la pena, puesto que el agente es neutralizado e internado en un centro de reclusión de por vida, si bien es cierto a los 35 años se revisa en audiencia dicha sanción vulnera el Principio de Humanidad y Racionalidad de las penas, la misma que debería establecerse en casos sumamente excepcionales.

En este sentido, (Mendoza Ayma, 2015) precisa:

Los operadores jurisdiccionales, no solo deben entrelazar permanentemente los conceptos de dogmática penal, con los postulados constitucionales e insumirlos de su contenido; sino que fundamentalmente deben tomar conciencia, de que ese vínculo tiene un objetivo: el fortalecimiento de diques de contención a la violencia ínsita del poder punitivo. (Pág. 32)

Ante la ausencia de una adecuada política criminal y la elevación desproporcionada de las consecuencias jurídicas del delito, a los jueces penales les compete emitir sentencias observando los principios de proporcionalidad y culpabilidad, los mismos que se encuentran 
previstos en la Constitución Política del Estado, estableciendo de este modo una contención a la violencia punitiva del Estado.

Conforme lo ha precisado el Tribunal Constitucional en STC. $\mathrm{N}^{\circ} 0019-2005-\mathrm{PI} / \mathrm{TC}$.

Es preciso destacar, sin embargo, que ninguna de las finalidades preventivas de la pena podría justificar que exceda la medida de la culpabilidad en el agente, la cual es determinada por el juez penal a la luz de la personalidad del autor y del mayor o menor daño causado con su acción a los bienes de relevancia constitucional protegidos. (Fundamento 41)

Por ello consideramos que es de vital importancia la labor de la judicatura, pero no es adecuado, inaplicar la norma penal invocando una afectación al principio de igualdad, cuando en realidad no se vulnera el mismo, originando que las consultas elevadas se desaprueben y se disponga la nulidad de las sentencias, debiendo dictarse nuevos fallos, originando inseguridad jurídica.

\section{ACUERDO PLENARIO No 4-2016/CIJ- 116}

En el Acuerdo Plenario $\mathrm{N}^{\circ} 4-2016$ de las Salas Penales Permanente y Transitorias de la Corte Suprema, de fecha 12 de junio de 2017, publicado el 17 de octubre de 2017, se abordaron las restricciones legales en materia de confesión sincera y responsabilidad restringida por edad, de conformidad con el artículo 116 de la Ley Orgánica del Poder Judicial, que faculta a la Corte Suprema de Justicia, pronunciar resoluciones vinculantes, con la finalidad de concordar y definir criterios jurisprudenciales, al respecto es menester precisar:

1. En el punto II se hace referencia a la evolución histórica, partiendo de las modificaciones introducidas al artículo 22 del Código Penal, por la ley $\mathrm{N}^{\circ} 27024$ del 25 de diciembre de 1998.

Se advierte que, en esta evolución histórica, no se ha considerado que el Código Penal de 1924, estableció en el artículo $148^{\circ}$ disposiciones que atenuaban la pena, respecto a los agentes de más de 18 y menos de 21 años de edad; y, mediante Ley $\mathrm{N}^{\circ} 15590$ del 20 de agosto de 1965, que reprimió el delito de traición a la patria, se prohíbe la aplicación de dicha atenuación, por consiguiente, este es el primer antecedente de un trato diferenciado en nuestra legislación en el caso que nos ocupa. También se ha omitido consignar como antecedente histórico, el artículo $10^{\circ}$ del Decreto Ley 25475, de fecha 5 de mayo de 1992, en el cual se restringe los alcances del artículo $22^{\circ}$ del Código Penal para los agentes por delito de terrorismo, norma que conjuntamente con los Decretos Leyes $\mathrm{N}^{\circ} 25659,25708,25880$, fueron objeto de Acción de Inconstitucionalidad, habiendo el Tribunal Constitucional declarado inconstitucional varios artículos, pero no emitió pronunciamiento respecto a dicho dispositivo legal.

2. El Acuerdo Plenario señala que el artículo 22 del Código Penal constituye una causal de disminución de la punibilidad, que se construye desde la estructura del delito, se precisa: "es una eximente imperfecta radicada en la categoría de culpabilidad" (Fundamento 9).

Al respecto debo señalar que no compartimos cuando se señala que este es un caso de eximente imperfecta de responsabilidad, puesto que ésta se presenta cuando no concurre alguno de los requisitos necesarios para hacer desaparecer totalmente la responsabilidad, en el presente caso, no se puede determinar qué requisito le faltaría al autor de 18 a 21 o mayor de 65 años, para eximirse de su responsabilidad penal.

Resulta ilustrativa la clasificación de eximentes propuesta por Pacheco y Groizard, citado por Mir Puig (2014):

Distingue en tres grupos de eximentes 1) las que consisten en un hecho indivisible, como la minoría de edad penal, 2) las que pueden fraccionarse o graduarse, aunque la ley no lo haya hecho, como el miedo insuperable, 3) las que se hallan fraccionadas por la ley, como la legítima defensa. Las primeras no podrían estimarse en forma incompleta, pero sí las de los dos grupos siguientes. (Pág. 619)

Lo expuesto coincide con nuestra postura respecto a que no se trata de una eximente incompleta.

Por su parte (Borja 2015 pág.60) precisa “sólo podrán ser consideradas como eximentes incompletas las que vienen enumeradas en 
de delitos graves y la jurisprudencia de las salas de la Corte Suprema

Responsibility restricted by age in the commissionon

serious crimes and the jurisprudence of the halls of the Supreme Court

el mencionado artículo 20, cuando en ellas falta alguno de los requisitos que la referida causa requiera para eximir totalmente la responsabilidad penal."

En la audiencia del 26 de agosto de 2016 del Pleno, no se analizó dogmáticamente esta disminución de punibilidad ni se expusieron consideraciones o fundamentos por los cuales debía ser considerada una eximente imperfecta, una causal de disminución de punibilidad y no una atenuante privilegiada.

Se precisa en el fundamento 10 del Acuerdo Plenario $N^{\circ}$ 4-2016/CIJ-116

El individuo no alcanza la madurez de repente y a los individuos entre 18 y 21 años no se les considera titulares de una capacidad plena para actuar culpablemente, pues su proceso de madurez no ha terminado; además en la edad avanzada del agente expresa un periodo de decadencia, de disminución de las actividades vitales, por lo que la capacidad de culpabilidad debe ser considerada como limitada.

Efectivamente, el individuo alcanza la madurez en un proceso paulatino, el mismo que varía de una persona a otra, muchas veces el agente no ha completado su desenvolvimiento mental o moral, siendo fuertemente influenciable.

La Constitución Política establece en el artículo 30, que son ciudadanos los peruanos mayores de 18 años, el artículo $42^{\circ}$ del Código Civil establece que tienen plena capacidad de ejercicio de sus derechos civiles las personas que han cumplido 18 años. Al respecto (Fernández 1990) precisa:

Que, de acuerdo a la realidad social, se supone, que a esa edad la persona está dotada de suficiente madurez intelectual, equilibrio psicológico, poder de reflexión y sentido de responsabilidad para ejercer, por sí misma y sin necesidad de asistencia, los derechos de que es capaz. (Pág. 112)

Lo que acontece es que muchas veces, no logra adecuar su comportamiento conforme a esa comprensión, le cuesta autodeterminarse para actuar conforme a derecho, en algunos, su ámbito de determinación es limitado, posee la inteligencia, pero en algunos casos no ha interiorizado adecuadamente los valores que deben observarse en la vida en comunidad.

Esta dificultad de adecuar su conducta conforme a derecho también se puede presentar con adultos de edad superior a los 21 años. Por otro lado, hay personas de 18 años a 21 años que poseen las facultades psíquicas y físicas para apreciar el carácter delictivo y determinarse según esta comprensión, ya que como hemos dicho la madurez es un proceso paulatino que varía de una persona a otra.

Por consiguiente, no debería considerarse como presunción absoluta, que todos los agentes entre 18 y 21 no han completado aún su desenvolvimiento mental o moral, para adecuar su conducta con arreglo a derecho, ya que ello no es coherente con las normas de nuestro ordenamiento legal; a esta conclusión, debe arribarse después de analizar las características personales del sujeto, la condición en la que se encontraba al momento de la comisión del delito y las circunstancias que rodearon el ilícito penal, puesto que el Juez al dictar sentencia debe resolver de conformidad con principios que inspiran el derecho, como los de legalidad, lesividad, proporcionalidad y culpabilidad, y tal como lo dispone el inciso h) del artículo $46^{\circ}$, modificado por la Ley 30076 que establece como circunstancia de atenuación "la edad del imputado en tanto que ella hubiere influido en la conducta punible" Oyarce (2016, p.92). Lo que también resulta aplicable tratándose del adulto mayor de 65 años de edad.

3. En el fundamento 14 precisa que esta diferenciación no está constitucionalmente justificada y que, en igual sentido, ya se ha pronunciado la Sala Constitucional y Social Permanente de la Corte Suprema, citando dos Consultas: 1260-2011 y 210-2012, que concluyen: "Las exclusiones resultan inconstitucionales y los jueces penales ordinarios no deben aplicarlas"

Al respecto es menester señalar, con respecto a las Consultas emitidas por la Sala Constitucional y Social de la Corte Suprema, si bien es cierto, en esas dos causas del año 2011 y 2012, se aprobaron las consultas, también es cierto, que en las demás consultas emitidas desde el 2009 al 
2014 se desaprobaron las sentencias que aplicaron el control difuso.

La audiencia pública del X Pleno se llevó a cabo el 28 de setiembre de 2016 y el Acuerdo Plenario $\mathrm{N}^{\circ} 4-2016$ se emitió el 12 de junio de 2017, durante los 7 meses y 15 días en los cuales se trabajó el Pleno, la Sala Constitucional y Social de la Corte Suprema expidió 73 resoluciones, en todas las cuales Desaprobaron las consultas efectuadas y se declararon nulas las sentencias emitidas, no obstante ello, estas resoluciones no fueron citadas o analizadas en el Acuerdo Plenario, pero sí se hizo alusión a las dos únicas resoluciones que aprobaron la consulta; advirtiéndose que, con posterioridad al citado Acuerdo Plenario, se han continuado desaprobando las consultas elevadas.

Por su parte, el Tribunal Constitucional al emitir sentencia en la Acción de Inconstitucionalidad interpuesta contra el Decreto Ley 25475 (Terrorismo) no declaró la inconstitucionalidad del artículo 10 que restringe los alcances del artículo 22 del Código Penal para los agentes del citado delito, habiendo declarado inconstitucionales otros artículos del citado dispositivo legal, pero no se pronunció expresamente sobre dicho artículo. Asimismo, en el proceso de Habeas Corpus $\mathrm{N}^{\circ} 751-2010$ en el cual se demanda la vulneración de los derechos a la libertad individual e igualdad, del sentenciado de 18 años de edad, por no haberse disminuido la pena por su edad, el Tribunal declaró infundada la demanda.

Resulta necesario relievar, que la Sala Penal Permanente de la Corte Suprema, ha emitido con fecha 3 de abril de 2019, la sentencia de Revisión $\mathrm{N}^{\circ} 188-2018$, en la cual declara fundada la demanda de revisión contra la Ejecutoria Suprema que condenó al autor del delito de terrorismo a 20 años de pena privativa de la libertad, por no haberse efectuado la disminución de la pena por responsabilidad restringida por la edad, imponiéndose una nueva pena, sentando un precedente a fin que puedan revisarse todas las sentencias en las cuales no se ha efectuado dicha atenuación.

Se advierte que la conclusión a la que arriba este Acuerdo Plenario, difiere con lo señalado en la sentencia de la Sala Constitucional y Social de la Corte Suprema, respecto a que el control difuso es inter partes y no es obligatorio.

\section{JURISPRUDENCIA DE LA SALA CONSTITUCIONAL Y SOCIAL DE LA CORTE SUPREMA}

La resolución de fecha 16 de agosto recaída en la Consulta $\mathrm{N}^{\circ}$ 1618-2016 Lima-Norte publicada el 7 de diciembre de 2017, derivada del control difuso que declaró inaplicable, el segundo párrafo del artículo $22^{\circ}$ del Código Penal, por ser incompatible con el artículo $2^{\circ}$, numeral 2 de la Constitución Política referido a la igualdad jurídica, en el proceso por delito contra el patrimonio, robo agravado, ha precisado, en resumen, lo siguiente:

1. El control difuso es una facultad de carácter excepcional y de última ratio, únicamente procede cuando no se puede salvar vía interpretativa la constitucionalidad de las normas, ya que estas gozan de presunción de legitimidad y constitucionalidad. Constituye un control con efecto inter partes, por ello, la aplicación del test de ponderación, están inescindible y obligatoriamente vinculados a los datos y particularidades, identificado los derechos fundamentales involucrados en el caso concreto, el medio utilizado, el fin perseguido, el derecho fundamental intervenido y el grado de intervención, para así poder aplicar el test de proporcionalidad.

2. Sobre la presunción de Constitucionalidad de la norma aplicada: La disposición legal precisa "Podrá reducirse prudencialmente la pena..." la norma no contiene mandato de reducción de la pena mínima legal en forma obligatoria e irrestricta para todos los agentes con responsabilidad restringida, lo cual exige del juez evaluación y determinación motivada, significando que, no siempre conllevará una reducción de la pena mínima legal. La vinculación a la pena legal es la regla general y el tratamiento diferenciado en la ley lo ocasiona el artículo 22 al crear una posibilidad para algunos agentes con imputabilidad restringida, supuesto normativo que se vincula y sustenta en los fines de la pena.

3. Toda restricción o tratamiento diferente en la ley no conlleva necesariamente una 
de delitos graves y la jurisprudencia de las salas de la Corte Suprema

Responsibility restricted by age in the commissionon

serious crimes and the jurisprudence of the halls of the Supreme Court

afectación al derecho a la igualdad, en tanto que la exigencia es el trato igual entre iguales, admitiendo un trato diferente entre desiguales, por ello señala que es necesario determinar: si es o no una diferencia no justificada de trato en la reducción de la pena, entre agentes de delitos con imputabilidad restringida, por razón del delito cometido.

Precisa que es posible realizar distinciones en base a criterios objetivos y razonables, el artículo 22 cumple dichas exigencias, la excepción es en razón de delitos graves y pluriofensivos. El trato diferente se justifica con los fines constitucionales de la pena, justificando la exclusión de la reducción de la pena mínima legal, para el agente que incurre en delitos graves que lesionan varios bienes protegidos constitucionalmente, como en el delito de robo agravado, por lo que, el tiempo requerido para los fines de la pena y reinserción con éxito a la sociedad, será mayor conteniendo una exigencia legítima y específica al mantener los límites legales de la pena cuando incurren en delitos de gravedad y pluriofensivos.

Concluye: Estamos ante un tratamiento jurídico desigual legítimamente establecido, compatible con los fines constitucionales de la pena, por lo que la norma en ninguna de sus regulaciones evidencia supuesto de inconstitucionalidad.

La sentencia consultada contiene argumentos en forma genérica que van orientados al control abstracto de la norma legal, lo cual no se encuentra en el supuesto previsto en el segundo párrafo del artículo 138 de la Constitución Política del Estado. Los jueces al inaplicar normas a casos particulares sin cumplir los supuestos para el control difuso, están vulnerando el principio de igualdad ante la ley, inaplicando injustificadamente y contra los fines del control difuso, la norma que contiene la prohibición de aplicar la reducción de la pena.

Resuelve que lo señalado, constituye doctrina jurisprudencial vinculante, para todos los jueces.

Se advierte que las resoluciones dictadas con posterioridad a la publicación de esta sentencia vinculante, no cumplen las disposiciones de la misma. Asimismo, esta contradicción se ha evidenciado en la Casación 1672-2017/ Puno, recaída en el proceso penal por delito de violación contra la libertad sexual en agravio de menor de edad, en el que, con fecha 30 de julio de 2014 se dictó sentencia condenatoria imponiendo 4 años de pena privativa de la libertad, declarándose inaplicable la restricción contenida en el artículo $22^{\circ}$ de Código Penal, la misma que fuera confirmada por la Sala Superior con fecha 27 de noviembre de 2014. Pero al elevarse la sentencia en consulta, la Sala Constitucional y Social Permanente de la Corte Suprema, desaprobó la sentencia que aplicó el control difuso, devueltos los autos, la Sala Penal, con fecha 23 de octubre de 2017, revocó la sentencia de primera instancia e impuso al sentenciado 6 años de pena privativa de la libertad.

La sentencia citada precedentemente, fue objeto de recurso de casación, con fecha 18 de octubre de 2018, la Sala Penal de la Corte Suprema, reconoció que las diferencias existentes entre el Acuerdo Plenario y la Ejecutoria Suprema de la Sala Constitucional son obvias y constituyen una antinomia, que debe resolverse aplicando el Acuerdo Plenario 4-1016/CIJ116. Evidenciándose la inseguridad jurídica derivada de las jurisprudencias contradictorias, situación que debe ser superada.

\section{CONCLUSIONES}

No existe un término de comparación válido para establecer que las restricciones incorporadas a la atenuación de la pena vulneran el principio de igualdad, ya que la situación fáctica no es análoga, para poder determinar que el sujeto ha sufrido un trato diferente.

La diferenciación efectuada por el artículo $22^{\circ}$ del Código Penal, se realiza teniendo como sustento la gravedad de algunos tipos penales y no en razón de las personas, un trato diferenciado vulnera el principio de igualdad cuando se encuentra desprovisto de justificación o cuando no es razonable ni proporcionado en atención a los fines que pretende alcanzar y es discriminatorio cuando la diferenciación se funda en las características inherentes a la persona, ya sea innatas, incorporadas o adoptadas, por consiguiente, no se vulnera el principio de igualdad ni son discriminatorias. 
El Estado viene ejerciendo su poder punitivo sin una adecuada política criminal, sin tener en consideración las investigaciones criminológicas y sin analizar los estudios de la dogmática penal, elevando desproporcionadamente las sanciones, "pretendiendo luchar contra la criminalidad".

Las personas que en el momento del hecho tienen dieciocho, pero aún no veintiún años, están equiparados a los adultos en cuanto a su imputabilidad. De igual modo los adultos mayores de 65 años de edad.

No debería considerarse como presunción absoluta, que todos los agentes entre 18 y 21 no han completado aún su desenvolvimiento mental o moral, para adecuar su conducta con arreglo al derecho o que los mayores de 65 años posean sus facultades disminuidas. La disminución de la pena debe efectuarse teniendo en consideración las condiciones que han rodeado el evento y las características del agente a fin de determinar si éstas han influido en la comisión del evento delictivo y por ende, existir un menor reproche o exigibilidad de adecuar su conducta conforme a derecho.

El legislador no debería restringir la atenuación facultativa de la pena en razón de la gravedad del delito, que guarda relación con la antijuricidad, puesto que el menor reproche que puede existir por la inmadurez del agente, afecta la culpabilidad, que es otro elemento del delito. Ello denota una inadecuada política criminal del Estado, que desconoce estudios dogmáticos penales, pero no por ello, afecta el principio de igualdad.

Desde el 26 de agosto de 2016, fecha en la que se llevó a cabo la audiencia pública del X Pleno, hasta el 12 de junio de 2017, que se emitió el Acuerdo Plenario transcurrieron 7 meses y 15 días, durante estos meses que se trabajó el Pleno, la Sala Constitucional y Social de la Corte Suprema expidió 73 resoluciones, en todas las cuales se desaprobaron las consultas efectuadas y se declararon nulas las sentencias emitidas, no obstante ello, estas no fueron citadas o analizadas en el Acuerdo Plenario, pero sí se hizo alusión a las dos únicas resoluciones que aprobaron las consultas emitidas hace más de 5 años.

Ante la ausencia de una adecuada política criminal y la elevación desproporcionada de las penas, a los jueces penales les compete emitir sentencias observando los principios de proporcionalidad y culpabilidad, los mismos que se encuentran previstos en la Constitución Política del Estado, estableciendo de este modo una contención a la violencia punitiva del Estado. Pero consideramos que no es adecuado, inaplicar la norma penal invocando una afectación al principio de igualdad, cuando en realidad no se vulnera el mismo.

El Acuerdo Plenario $N^{\circ}$ 04-2016 de las Salas Penales y la Sentencia en la Consulta $\mathrm{N}^{\circ}$ 1618-2016 de la Sala Constitucional y Social de la Corte Suprema, han establecido que son vinculantes, pero sus conclusiones son disimiles, lo que genera inseguridad jurídica.

\section{FUENTES DE INFORMACIÓN}

\section{Fuentes bibliográficas}

Borja Jimenez, Emiliano (2015). La aplicación de las circunstancias del delito. (Valencia), España: Tirant lo Blanch.

Cury Urzúa, Enrique (2005). Derecho Penal Parte General. (Santiago de Chile), Chile: Ediciones Universidad Católica de Chile.

Fernandez Sessarego Carlos (1990). Derecho de las Personas. (Lima), Perú: Cultural Cuzco.

Gutiérrez Ticse, Gustavo (2010). La Constitución Política del Perú, interpretada por la jurisprudencia del Tribunal Constitucional. Lima, Perú: Editorial Grijley.

Hurtado Pozo, José (2011). Manual de Derecho Penal - Parte General. (Lima), Perú: Editorial Grijley.

Polaino Navarrete, Miguel (2015). Derecho Penal - Parte General. (Lima), Perú: ARA Editores.

Mantovani, Ferrando (2015). Los Principios del Derecho Penal. (Lima), Perú: Ediciones Legales.

Maurach Reinhart (1994). Derecho Penal Parte General, $7^{\circ}$ edición. Buenos Aires, Argentina: Editorial Astrea.

Meini, Iván (2014). Lecciones de Derecho Penal - Parte General. (Lima), Perú: Fondo Editorial Pontificia Universidad Católica del Perú. 
Mendoza Ayma, Francisco (2015). Determinación e Individualización de la Pena. (Lima), Perú: Jurista Editores EIRL.

Mir Puig Santiago (2014). Derecho Penal-Parte General. (Barcelona), España: TECFOTO, SL.

Prado Saldarriaga, Víctor (2015). Determinación Judicial de la Pena. Lima, Perú: Instituto Pacífico.

Roxin Claus (2014). Derecho Penal Parte General - Tomo I. Madrid, España: Civitas Ediciones.

Villavicencio Terreros, Felipe (2012). Derecho Penal Parte General. (Lima), Perú: Editorial Grijley.

\section{Fuentes hemerográficas}

Lascurain, Juan Antonio (2011). Sobre la igualdad penal. En Gaceta Penal\& Procesal Penal, Tomo 21, pp.57-73

Rodriguez Collao, Luis (2011). Naturaleza y fundamento de las circunstancias modificatorias de la responsabilidad criminal. Revista de Derecho de la Pontificia Universidad Católica de Valparaíso, XXXVI, 2011, $1^{\circ}$ Semestre, pp. 397-428.

\section{Fuentes electrónicas}

Cerdá Martinez-Pujalte, Carmen María (2005). Los principios Constitucionales de igualdad de trato de prohibición de la discriminación. Recuperado de http://www.corteidh.or.cr/ tablas/r23276.pdf
Caro Coria, Dino (2017). Notas sobre la individualización judicial de la pena en el Código Penal peruano. Recuperado de https://www.ccfirma.com/wp-content/ uploads/2017/11/IJP-Carlos-Caro.pdf

Prado Saldarriaga, Victor (2015) Las Circunstancias Atenuantes Genéricas del artículo 46 Del Código Penal. Recuperado de http://revistas.pucp.edu.pe/index.php/themis/ article/view/15579/16028

González Le Saux, Marianne y Parra Vera, Oscar (2008) Concepciones y cláusulas de igualdad en la jurisprudencia de la Corte Interamericana. A propósito del Caso Apitz. Recuperado de http://www.corteidh.or.cr/ tablas/r23826.pdf

\section{Jurisprudencia}

Tribunal Constitutional (2006). STC. Exp. 0004-2006-PI/TC. Recuperado de http://www. tc.gob.pe/jurisprudencia/2006/00004-2006AI.pdf

Tribunal Constitucional (2004). STC. Exp. 0606-2004-AA/TC. Recuperado de http:// www.tc.gob.pe/jurisprudencia/2005/006062004-AA.pdf

Tribunal Constitucional (2014). STC. Exp. 05157-2014-PA/TC. Recuperado de http:// www.tc.gob.pe/jurisprudencia/2017/051572014-AA.pdf

Tribunal Constitucional (2005). STC. Exp. 0019-2005-PI/TC. Recuperado de https:// www.tc.gob.pe/jurisprudencia/2005/000192005-AI.pdf 